\title{
O PODER DOS SEM-PODER NO BLACK BLOC: UMA TÁTICA DE ENFRENTAMENTO ANTICAPITALISTA CONTRA OS PRINCIPADOS DA DOMINAÇÃO
}

The power of the without power in the black bloc: an anticapitalist face against the principalities of domination

Jan Clefferson Costa de Freitas ${ }^{1}$

Resumo: Maquiavel advoga a manutenção da ignorância sobre as massas como uma forma de manter os súditos do príncipe bem comportados. Merleau-Ponty apresenta a omissão da verdade enquanto alienação como uma medida de dominação no pensamento maquiavelista. O Black Bloc é uma tática de enfrentamento anticapitalista na luta das ruas contra os poderes instituídos pelas autoridades e que se faz totalmente contra o princípio da dominação. Por mais de duas décadas os Black Blocs ao redor do mundo têm feito com que os príncipes da tirania contemporânea não tenham sono. Isso se deve ao fato de que os povos não querem morrer de cabeça baixa sendo explorados pelos tiranos. A tendência atual que se faz presente nas manifestações reivindicatórias é a luta organizada, em oposição à opressão deliberada pelos facínoras contra o povo. Isso evidencia o que pode o povo desprovido de poder quando se faz organizar para enfrentar os asquerosos. Uma verdadeira ameaça ao poder dos com-poder se faz aparecer para abolir os privilégios dos poderosos. Pretende-se apresentar no presente artigo uma explanação mais sucinta de tal discussão.

PALAVRAS-CHAVE: Black Bloc; Dominação; Poder.

ABSTRACT: Machiavelli advocates maintaining ignorance upon the masses as a way to keep the prince's subjects well behaved. Merleau-Ponty presents the omission of truth as alienation as a measure of domination in Machiavellian thought. Black Bloc is a tactic of anticapitalist confrontation in the struggle of the streets against the powers instituted by the authorities and that is totally against the principle of domination. For more than two decades Black Blocs around the world have made the princes of contemporary tyranny not sleepy. This is due to the fact that people do not want to die with low heads being exploited by tyrants. The current tendency that is present in the protests is the organized fight, as opposed to the deliberate oppression by the scoundrels against the people. This shows what the powerless people can do when it is organized to confront the disgusting. A real threat to the power of those with power is made to abolish the privileges of the powerful. It is intended to present in this article a more succinct explanation of such discussion.

KEYWORDS: Black Bloc; Domination; Power.

"Os que vivem são aqueles que lutam."

Victor Hugo

\footnotetext{
${ }^{1}$ Doutorando em Filosofia - UFPB-UFPE-UFRN
} 
Além de postular-se contrariamente aos bons sentimentos na política, paradoxalmente Maquiavel [1469-1527] também é contra a violência (MERLEAUPONTY, 1991, p. 237). A pura coação do poder político é o que sustentaria de imediato a vida coletiva no acaso convencional da humanidade: uma vez que a função de qualquer governo é impor o respeito aos súditos, as boas leis - segundo pensa Merleau-Ponty [19081961] sobre Maquiavel - são feitas pelas boas tropas (MERLEAU-PONTY, 1991, p. 237), sendo a arte de governar um exercício estratégico das artes bélicas (MAQUIAVEL, 2013, p. 94). O infortúnio projetado sobre a vida coletiva diariamente vai fomentando a rivalidade, de modo que entre os súditos e o poder, apenas duas escolhas podem ser feitas, a saber: ou agride-se e oprime-se; ou é-se agredido e oprimido (MERLEAU-PONTY, 1991, p. 237). Constantemente sob a ameaça de contestação, o poder busca manter os cidadãos com a razão entorpecida.

A opinião geral considera o poder como dado - desde que o lado injustificável da tirania não se exprima -, a legitimidade do poder é outorgada quando este não faz surgir o desprezo e o ódio: a total agressão causaria desdém e a completa opressão causaria revolta (MERLEAU-PONTY, 1991, p. 239); isto é, apenas episodicamente a violência pode ser pura, pois o povo está buscando se livrar da tirania, ao passo que os opressores estão sempre a executá-la. Os poderosos estão querendo comandar e oprimir a população, que por sua vez, não procura ser oprimida e nem comandada pelos privilegiados - um fenômeno político habilitado a instituir em uma cidade, como consequência dessa tensão entre desejos antagônicos: a liberdade, a rebelião ou o principado (MAQUIAVEL, 2013, p. 77). Para Maquiavel (MERLEAU-PONTY, 1991, p. 242), o poder social tem origem nos conflitos e nas lutas, mas acordos também são possíveis, sendo a materialização do poder popular a participação comum em uma dada situação.

A crueldade, para poder manter os súditos bem comportados, não deve pelo príncipe ser receada, pois a indulgência excessiva, motiva agitações e rapinagens. O Estado é abalado completamente pelas rebeliões: as punições individuais executadas pelo príncipe contra os rebeldes só fomentam o castigo para alguns, ao invés de acabar indistintamente com todo mundo (MERLEAU-PONTY, 1991, p. 243). As adversidades são governadas pela força do atraso que se sustenta sobre a renúncia da compreensão e da vontade. Justiça e liberdade são valores pelos quais muitos em luta se colocam: quer sejam estes senhores ou quer sejam estes escravos, a distinção entre ambos será, somente, aquela que demonstra as suas formas de poder efetivar os seus direitos. 
Merleau-Ponty, em sua Nota Sobre Maquiavel, escrita em seu livro Signos [1960], narra casos históricos nos quais o povo se rebelou contra a tirania de seus governantes, apresentando como em certas situações a aplicação de princípios ideológicos serviu apenas para oprimir a sociedade (MERLEAU-PONTY, 1991, p. 247), as revoltas populares são incitadas por ocasiões nas quais a pluralidade se sente oprimida, necessitando se levantar contra os tiranos que a oprime: Merleau-Ponty concorda com Maquiavel quando para ele este pensa que "é preciso ter valores, mas não basta, e até é perigoso restringir-se a isso; enquanto não se escolherem aqueles que têm a missão de sustentá-los na luta histórica, nada se fez" (MERLEAU-PONTY, 1991, p. 248), ou seja: tais princípios não apenas precisariam ser bem escolhidos, mas também necessitariam ser bem aplicados (MERLEAU-PONTY, 1991, p. 250), pois não adianta ter-se um princípio sem aplicação, muito menos aplicá-lo maldosamente.

É verdade que Maquiavel se deteve sobre o problema do poder, mas não é mentira que para a definição de um poder que fosse justo, o pensador não despendeu muita energia (MERLEAU-PONTY, 1991, p. 249). Merleau-Ponty considera que, para Maquiavel, "haverá sempre duas espécies de homens, aqueles que vivem e aqueles que fazem história" (MERLEAU-PONTY, 1991, p. 249). Em outras palavras, Maquiavel teoriza que, segundo postula Merleau-Ponty, se existem de um lado, figuras históricas e de outro, figuras viventes, faz-se preciso que os primeiros pratiquem a arte coercitiva de governarem sobre os segundos, para que estes se aliem aos primeiros (MERLEAUPONTY, 1991, p. 249). Onde está o lado humano de um poder que não se aproxima da humanidade? A resposta dessa questão se encontra na exiguidade de um humanismo, na filosofia de Maquiavel, que seja capaz de reconhecer efetivamente através do mundo o ser humano enquanto tal.

Esse tipo exíguo de humanismo, atualmente possui existência e, Merleau-Ponty, identifica na obra de Marx uma retomada das questões que foram abertas por Maquiavel, referentes à possibilidade de um humanismo real, independente do apoio sobre o equívoco dos princípios ideológicos, de uma humanidade que seja capaz de suprimir a opressão exploradora para acabar com a exploração opressora (MERLEAU-PONTY, 1991, p. 250). O problema central dessa reflexão foi sobre a constituição de "um poder dos sem-poder" (MERLEAU-PONTY, 1991, p. 250): sem o poder ser anulado, figurou-se necessário que, para controlarem o poder, formas políticas eficazes seriam precisas, desde que capazes de manterem contato com as frações oprimidas do povo, e levá-las a consolidarem a sua autonomia, pois "todo poder tende a autonomizar-se" (MERLEAU-PONTY, 1991, p. 
251). Apesar de todos os pesos, considerando o efeito pedagógico das revoluções que desmoronaram sobre a cabeça dos humanistas, "o problema de um humanismo real está intacto, e, portanto, mostra indulgência para com Maquiavel, que não podia senão entrevêlo" (MERLEAU-PONTY, 1991, p. 250). É preciso esquadrinhar cada vez mais Maquiavel para poder compreender com nitidez os desdobramentos contemporâneos de sua própria filosofia.

Se Maquiavel era ou não um humanista, faz-se imprescindível considerar que, para poder afirmar isso, é necessário perscrutar os aspectos importantes de seu pensamento, recortes nos quais a humanidade se encontra em relação com ela mesma, vivenciando situações históricas que lhe sejam concomitantes ao ideal humanitário (MERLEAUPONTY, 1991, p. 251). Do contrário, ao considerar que seja rejeitada em Maquiavel a existência de um humanismo, é possível constituir essa rejeição a partir do pressuposto de que há uma sucessão de dificuldades nas relações interpessoais em seu pensamento, na qual a exortação moral é substituída pela cultura política, aumentando a opacidade no funcionamento social (MERLEAU-PONTY, 1991, p. 251). De qualquer modo, pode-se considerar Maquiavel como um pensador que molda os blocos da seriedade de um humanismo legítimo, assim como é possível excisar de seu pensamento uma decisão que vai de encontro aos pressupostos de um autêntico humanismo.

A expressão Black Bloc define "uma forma específica de ação coletiva, uma tática que consiste em formar um bloco em movimento no qual as pessoas preservam o seu anonimato, graças, em partes, às máscaras e roupas pretas” (DUPUIS-DÉRI, 2014, p. 10). Enquanto tática de enfrentamento anticapitalista, o Black Bloc oferece voz para as pessoas que protestam contra os tiranos, para que estas encontrem "a oportunidade de expressar uma crítica radical ao sistema” (DUPUIS-DÉRI, 2014, p. 11) e, sendo vedado ao príncipe que este, sob a pena de ser depauperado, permita alguém falar com transparência (MERLEAU-PONTY, 1991, p. 241), a segurança do anonimato oferecida pela tática Black Bloc oferece para o povo a efetividade de sua revolta contra os principados.

É muito fácil para aqueles que ocupam as posições privilegiadas - como os príncipes, por exemplo -, serem contra a violência, pois os patifes não estão morrendo à míngua de hemoptise nas calçadas, com expectorações sangrentas, nem estão sendo chacinados nas periferias por mercenários sem identidade, os capatazes do principado leviatânico (BRITO, 2013, p. 66); mas para aqueles que todos os dias estão sendo violentados pelo Estado, fica complicado defender uma moralidade que não seja violenta (ZIZEK, 2012, p. 17): os Black Blocs sensibilizam os excluídos alimentados pelo pão que o 
diabo amassou, libertando-os da condenação à servidão, e os fazendo agirem concretamente sobre o objeto de sua revolta (NED LUDD, 2002, p. 81). Em poucas palavras, essa tática de enfrentamento contra a opressão é uma forma de resposta e resistência dos sem-poder à agressão, arbitrariamente deliberada contra o povo pelos parasitas.

Ninguém no ano de 2013 no Brasil imaginaria o que iria acontecer naqueles meses que o povo brasileiro acabou de ver passar. Desde o ano de 2004 que os ativistas do Movimento Passe Livre estavam articulando várias movidas de ação direta nos centros urbanos do país, dentre os quais Florianópolis estava no ranking das cidades mais insurgentes, barrando os aumentos consecutivos das passagens de transporte no território da União (VINICIUS, 2005, p. 9): nas Jornadas de Junho, conforme consta no The New York Times, Natal ocuparia uma posição tão importante quanto antes Florianópolis, acendendo a fagulha provocadora da polvorosa que se alastrou naquele ano da história brasileira. Isso para dizer que os aumentos da passagem de transporte são atos despóticos, realizados na calada da noite contra a população pelos asquerosos, o que leva o povo a se revoltar profundamente contra os tiranos no poder, exigindo a erradicação mais que imediata da fantasmagoria espoliadora instituída pelos canalhas: foi o que aconteceu em 2013 por todo o Brasil.

Fez-se preciso que houvesse naquele momento uma tática capaz de canalizar as aspirações do povo de uma maneira satisfatória para o combate da excruciante repressão executada pelos governantes através dos anos que se passaram: o Black Bloc funcionou perfeitamente para isto (NED LUDD, 2002, p. 116). A ausência de diálogos com a população por parte dos governantes motivou a rebeldia iconoclasta dos Black Blocs e consolidou o protagonismo político desta tática durante as Jornadas de Junho no ano de 2013 (JUDENSNAIDER, 2013, p. 37). A pensar por analogia, o Black Bloc constitui uma tática que consolida a manifestação concreta do poder dos sem-poder. uma vez que autonomiza o poder popular, o libertando da opressão e suprimindo a exploração (MERLEAU-PONTY, 1991, p. 251), permite uma elevação dos oprimidos diretamente contra os opressores, oferecendo uma demonstração do potencial revolucionário dos explorados que se unificam (DUPUIS-DÉRI, 2014, p. 121). O Black Bloc é uma possibilidade tática para a prática episódica do poder dos sem-poder.

“O poder é da ordem do tácito” (MERLEAU-PONTY, 1991, p. 239), isto é, não se pode senti-lo sem que o mesmo se manifeste, não se pode contestá-lo até que ele se explicite (MERLEAU-PONTY, 1991, p. 239): “as vítimas crônicas da injustiça flagrante do 
capitalismo [...], vítimas do horror patriarcal [...] que transformou os seres humanos em mercadorias" (NED LUDD, 2002, p. 137), são as provas concretas de como o poder funciona, do que é o poder quando ele se mostra. Merleau-Ponty trata a questão dos súditos em Maquiavel como se estes estivessem neste mundo muito à parte do poder: "As relações entre o súdito e o poder, como aquelas entre o eu e o outro, travam-se mais fundo do que o juízo, sobrevivem à contestação, enquanto não se tratar da contestação radical do desprezo" (MERLEAU-PONTY, 1991, p. 239). Em uma rápida mirada, o poder para o povo não foi incluso na obra de Maquiavel, pois este não considera que o povo seja histórico, acreditando que o povo apenas vive, sendo os príncipes por excelência as figuras históricas, e o povo por consequência as figuras viventes.

A tática Black Bloc faz de si a manifestação "da contestação radical do desprezo" (MERLEAU-PONTY, 1991, p. 239) pelo poder pretensamente soberano das hierarquias autoritárias e desumanas, pois mesmo com a mídia assumindo posições atrasadamente conservadoras e mentirosas em relação às manifestações anticapitalistas em todo o planeta (OLIVEIRA, 2013, p. 7), há inclusive manifestantes não violentos que são favoráveis à violência, pois estes entendem que esta os defende da brutal intervenção da repressão totalitária (DUPUIS-DÉRI, 2014, p. 101). Em outras palavras, a tática Black Bloc possibilita uma sofisticada articulação para os sem-poder, que torna realizável a resistência no enfretamento contra os verdadeiros opressores e agressores, a saber, os dirigentes dos mecanismos de coibição que são operados pelo Estado e acionados pelos governos, uma reposta radical à canalhice deste mundo.

Se o objetivo de um governo é impor o respeito aos súditos (MERLEAUPONTY, 1991, p. 237), é um dever para os cidadãos não aceitar essa imposição, abandonando a posição de oprimidos, ao se tornar independentes dos governos, questionando as discriminações cotidianas, com propaganda através da ação (NED LUDD, 2002, p. 86): “o alvo é a mensagem” (DUPUIS-DÉRI, 2014, p. 97), e o Black Bloc sabe onde realizar os seus ataques, não atacando as pequenas empresas de pessoas tão exploradas quanto eles, os "seus ataques se concentram contra os símbolos das grandes corporações" (DUPUIS-DÉRI, 2014, p. 98): os bancos, as multinacionais, as instituições da desigualdade, os espaços referenciais para os poderosos, tudo isso é desafiado pela tática Black Bloc, que pelo menos de maneira temporária faz calar as injustiças.

A constante ameaça de contestação sofrida pelo poder, descrita por Maquiavel em O Príncipe [1513] (MERLEAU-PONTY, 1991, p. 238), necessita para ele ser repelida, e para isso é necessário que o poder não se transforme na expressão de uma vontade individual, 
mantendo-se como um tipo de opinião geral a qual se fez cristalizar (MERLEAU-PONTY, 1991, p. 239). Dito de outra maneira, para manter os cidadãos adormecidos, não é o dever do poder coagi-los, mas aliciá-los ao apelar pela liberdade, no lugar de aterrorizar para persuadir (MERLEAU-PONTY, 1991, p. 239). O Black Bloc esfacela a cristalização de uma opinião geral para formular uma perspectiva de resistência contra a aliciação executada pelo poder sobre a vontade dos indivíduos.

$\mathrm{Na}$ grande maioria das vezes, as ações diretas do Black Bloc são movidas pela coerência ideológica dos ativistas aderentes a essa tática; outras vezes, porém, as emoções da coletividade realizam ações que são consideradas irracionais pelos defensores de privilégios (JUDENSNAIDER, 2013, p. 40), “mas esse impulso emocional são significa que essas ações não tenham racionalidade econômica ou política" (DUPUIS-DÉRI, 2014, p. 120) - muito pelo contrário: nutrir desprezo pelos privilegiados e sentir prazer ao tornálos insones é um direito para quem vive sendo explorado todos os dias, e é por isso que "um dos deveres do príncipe é resolver as questões antes que elas tenham se tornando insolúveis pela emoção dos súditos” (MERLEAU-PONTY, 1991, p. 238), pois aonde o povo avança, a burguesia retrocede; em poucas palavras, quando o povo se revolta, o príncipe a ele se volta.

Os meios adotados pelos dirigentes da opressão para governar sobre a vida dos povos continuam violentos (MERLEAU-PONTY, 1991, p. 249), com a diferença de que hoje em dia as agressões estão ficando mais atrozes, não obstante maquiadas pela película da lei (MERLEAU-PONTY, 1991, p. 238), visto que as ditas sociedades democráticas contemporâneas nada mais são do que disfarces para a tirania (AVELINO, 2014, p. 13), ao exporem suas verdadeiras faces: um Estado Sem Direitos no qual aqueles que se colocam contra os interesses dos governantes são, em primeiro lugar, perseguidos e intimidados; em segundo lugar, presos e torturados; e em terceiro lugar, sequestrados e assassinados (FREITAS, 2013, p. 50) - mencionando os casos recentes ocorridos nas Revoltas de Junho (AVELINO, 2014, p. 5) como exemplos desta cruel constatação: Amarildo Dias de Souza e Júlia Coller exemplificam a fatalidade.

Para não ter que aprofundar infinitamente mais estas questões, pode-se concluir que a tática Black Bloc constitui uma das formas de resistência do poder dos sem-poder (MERLEAU-PONTY, 2002, p. 250), uma maneira de resistir às agressões sistematicamente deliberadas pelos tiranos contra o povo (NED LUDD, 2002, p. 79), um meio pelo qual é possível para as massas resistirem às opressões cotidianas perpetuadas contra elas (DUPUIS-DÉRI, 2014, p. 85); em síntese: Maquiavel advoga a manutenção da ignorância 
sobre as massas como uma forma de manter os súditos do príncipe bem comportados (MAQUIAVEL, 2013, p. 104). Merleau-Ponty apresenta a omissão da verdade enquanto alienação como uma medida de dominação no pensamento maquiavelista (MERLEAUPONTY, 1991, p 239). O Black Bloc é uma tática de enfrentamento anticapitalista na luta das ruas contra os poderes instituídos pelas autoridades e que se faz totalmente contra o princípio da dominação (NED LUDD, 2002, p. 135). Por mais de três décadas os Black Blocs ao redor do mundo têm feito com que os príncipes da dominação contemporânea não tenham sono (DUPUIS-DÉRI, 2014, p. 40). Isso se deve ao fato de que os povos não querem morrer de cabeça baixa sendo oprimidos e explorados pelos príncipes (MERLEAU-PONTY, 1991, p. 241), os decadentes do capitalismo crepuscular. A tendência sempre atual que se faz presente nas manifestações reivindicatórias é a luta contra a tirania (FREITAS, 2013, p. 48). Isso evidencia o que pode o povo desprovido de poder quando se faz organizar para enfrentar os seus tiranos. Uma verdadeira ameaça para o poder dos com-poder se faz emergir vindo retirar dos poderosos os seus privilégios. Foi objetivo do presente artigo, oferecer uma explanação mais sucinta de tal discussão.

\section{REFERÊNCIAS}

AVELINO, Nildo. Violência, Democracia e Black Blocs: As Revoltas de Junho no Brasil e o Anarquismo. Coletivo Nenhures. Acari. 2014.

DUPUIS-DÉRI, Francis. Black Blocs. Tradução: Guilherme Miranda. Veneta Editora. São Paulo. 2014.

FREITAS, Jan Clefferson Costa de. Da Revolta do Busão para a História do Brasil: Do Maio de 1968 ao Junho de 2013. Editado pelo autor. Natal. 2013.

HARVEY, David. TELES, Edson et al. Occupy: Movimentos de Protesto que Tomaram as Ruas. Boitempo Editorial. São Paulo. 2012.

JUDENSNAIDER, Elena. LIMA, Luciana et al. Vinte Centavos: A Luta contra o Aumento. Veneta Editora. São Paulo. 2013.

MAQUIAVEL, Nicolau. O Príncipe. Tradução: Maurício Santana Dias. 4ª Reimpressão. Peguin/Companhia das Letras. São Paulo. 2013.

MERLEAU-PONTY, Maurice. Signos. Tradução: Maria Ermantina Galvão Gomes Pereira. Livraria Martins Fontes Editora Ltda. São Paulo. 1991. 
NED LUDD, Org. Urgência das Ruas: Black Bloc, Reclaim the Streets e os Dias de Ação Global.

Tradução: Leo Vinicius. Coleção Baderna. Conrad Editora do Brasil. São Paulo. 2002.

OLIVEIRA, Vantiê Clíncio Carvalho de. Sobre a(s) Radicalidade(s) Libertária(s): Da Estratégia de Desmobilização, Passando pela de Pacificação e Domesticação e Culminando na Conciliação Nacional Reformista: Uma Análise das Respostas do Status Quo à Recente Onda de Protestos no Brasil. Coletivo Nenhures. Acari. 2013.

VAINER, Carlos. HARVEY, David et al. Cidades Rebeldes: Passe Livre e as Manifestações que Tomaram as Ruas do Brasil. Boitempo Editorial. São Paulo. 2013.

VINICIUS, Leo. A Guerra da Tarifa. Faísca Publicações Libertárias. São Paulo. 2005.

VINICIUS, Leo. Guerra da Tarifa 2005: Uma Visão de dentro do Movimento Passe-Livre em Floripa. Faísca Publicações Libertárias. São Paulo. 2006. 